J. Lake Sci. (湖泊科学), 2019, 31(1): 88-98

DOI 10. 18307/2019. 0109

(c) 2019 by Journal of Lake Sciences

\title{
太湖流域降雨和湖水酸根阴离子长期变化及其环境意义
}

\author{
赵 健 ${ }^{1}$, 代 丹 $^{1,2}$, 王 瑞 $^{3}$, 郝晨林 ${ }^{1}$, 何成达 ${ }^{3}$, 于 涛 ${ }^{3 * *}$ \\ (1: 中国环境科学研究院, 北京 100012) \\ (2: 北京师范大学水科学研究院, 北京 100875 ) \\ (3:扬州大学环境科学与工程学院,扬州 225217)
}

\begin{abstract}
摘 要: 为揭示太湖流域降雨和湖水酸根阴离子长期变化特征及环境意义, 通过历史数据收集和采样分析, 对太湖流域 降雨和湖水中的 $\mathrm{SO}_{4}^{2-} 、 \mathrm{NO}_{3}^{-}$变化特征和来源进行了研究. 结果表明: 自 $1990 \mathrm{~s}$ 以来太湖流域降雨中 $\mathrm{SO}_{4}^{2-}$ 呈显著下降趋势, 年平均下降率为 $0.28 \mathrm{mg} /(\mathrm{L} \cdot \mathrm{a})$; $\mathrm{NO}_{3}^{-}$浓度却呈显著上升趋势, 年平均增长率为 $0.05 \mathrm{mg} /(\mathrm{L} \cdot \mathrm{a})$, 降雨中氮污染呈现加重 的趋势. 与之相反, 湖水中 $\mathrm{SO}_{4}^{2-}$ 呈显著上升趋势, 年平均增长率为 $1.24 \mathrm{mg} /(\mathrm{L} \cdot \mathrm{a}) ; \mathrm{NO}_{3}^{-}$浓度却呈显著下降趋势, 年平均下 降率为 $0.02 \mathrm{mg} /(\mathrm{L} \cdot \mathrm{a}) .30$ 年以来, 太湖水体 $\mathrm{SO}_{4}^{2-} / \mathrm{NO}_{3}^{-}$比值不断升高, 远高于降水 $\mathrm{SO}_{4}^{2-} / \mathrm{NO}_{3}^{-}$比值. 研究认为: 流域 $\mathrm{SO}_{2}$ 排放引起的酸沉降是湖水 $\mathrm{SO}_{4}^{2-}$ 浓度增长的最重要原因, 但氮氧化物排放并未引起湖水 $\mathrm{NO}_{3}^{-}$浓度升高, 说明太湖流域对大 气沉降的氮氧化物有滞留作用, 而太湖水体是流域大气沉降硫酸盐的重要汇. 综合治理太湖流域酸性物质排放对防止太 湖水体酸化和治理富营养化都具有重要意义.
\end{abstract}

关键词: 酸根阴离子;酸沉降; 富营养化; 降雨;太湖

\section{Long-term trends of acid anion in the rain water in Lake Taihu watershed and the lake water, and its environmental implications}

\author{
ZHAO Jian ${ }^{1}$, DAI Dan ${ }^{1,2}$, WANG Rui ${ }^{3}$, HAO Chenlin ${ }^{1}$, HE Chengda ${ }^{3} \& \mathrm{YU} \mathrm{Tao}^{3 * *}$ \\ (1: Chinese Research Academy of Environmental Sciences, Beijing 100012, P.R.China) \\ (2: College of Water Sciences, Beijing Normal University, Beijing 100875, P.R.China) \\ (3: College of Environmental Science and Technology, Yangzhou University, Yangzhou 225217, P.R. China)
}

Abstract: To explore long-term trends of acid anions in the rain water in Lake Taihu watershed, the lake water and their environmental implications, the variation characteristics, sources and the relationships of $\mathrm{SO}_{4}^{2-}, \mathrm{NO}_{3}^{-}$in the rain water and the lake water were studied via historical data collection and sampling analysis. The results indicated that $\mathrm{SO}_{4}^{2-}$ in the rainwater showed a significant decreasing trend since 1990s with an annual average decrease rate of $0.28 \mathrm{mg} /(\mathrm{L} \cdot \mathrm{a})$, and the $\mathrm{NO}_{3}^{-}$showed a significant increasing trend with an annual average increase rate of $0.05 \mathrm{mg} /(\mathrm{L} \cdot \mathrm{a})$, which suggests an aggravating trend of nitrogen pollution in the rain water. In contrast, $\mathrm{SO}_{4}^{2-}$ in the lake water showed a significant increasing trend with an annual average increase rate of 1.24 $\mathrm{mg} /(\mathrm{L} \cdot \mathrm{a})$, and the $\mathrm{NO}_{3}^{-}$showed a significant decreasing trend with an annual average decrease rate of $0.02 \mathrm{mg} /(\mathrm{L} \cdot \mathrm{a})$. During the past 30 years, the ratio of $\mathrm{SO}_{4}^{2-} / \mathrm{NO}_{3}^{-}$in Lake Taihu water continuously increased, much higher than that of the rain water. The research indicated that the acid deposition caused by $\mathrm{SO}_{2}$ emissions in the watershed was mainly responsible for the increased concentration of $\mathrm{SO}_{4}^{2-}$ in the lake water. However, the nitrogen oxides emissions did not cause an increase concentration of $\mathrm{NO}_{3}^{-}$in the lake water, indicating that Lake Taihu watershed plays a significant role in the retention of nitrogen deposition, while the lake water is an important sink for sulfate deposition. The regional nitrogen deposition has an important impact on Lake Taihu water eutrophication. It is of great significance to prevent the acidification and eutrophication in Lake Taihu via comprehensive management of

* 国家水体污染控制与治理科技重大专项 (2018ZX07208001,2017ZX07301003) 和中国环境科学研究院环境基准与 风险评估国家重点实验室基金项目 (SKLECRA20160FP11, SKLECRA2017OFP01) 联合资助. 2018-05-25 收稿; 2018-07-10 收修改稿. 赵健 (1979 ), 男,博士, 副研究员; E-mail: zj103823@ 163.com.

** 通信作者;E-mail: yutao0325@ sina.com. 
acid emissions in Lake Taihu watershed.

Keywords: Acid anions; acid deposition; eutrophication; rainwater; Lake Taihu

大气酸沉降引起的淡水水体酸化已成为一个全球性的热点问题 ${ }^{[1-3]}$. 酸沉降引起的淡水水体酸化集中 表现在水体 $\mathrm{SO}_{4}^{2-}$ 浓度增加, 碱度和 $\mathrm{pH}$ 下降 ${ }^{[2,4]}$, 使水体水化学特征发生改变, 并对水生生物产生不利影 响 ${ }^{[5]} .1970 \mathrm{~s}$ 年底, 我国西南地区是最早出现酸雨问题的片区 ${ }^{[6]}$, 经过多年的发展, 我国已成为继欧洲和北美 之后的世界三大酸雨区之一, 酸雨分布区域主要集中在长江沿线及中下游以南 ${ }^{[7]}$. 截止 2014 年, 我国酸雨 区面积约占国土面积的 10.6\%, 酸雨污染形势严峻 ( http://env. people. com. cn/n/2014/0604/c101025103121.html). 早在 20 世纪初, Chen 等 ${ }^{[8]}$ 的研究就已表明: 长江中上游地区水质变化与大气环境的酸化 之间存在较好的因果关系, $\mathrm{SO}_{2}$ 排放是水体 $\mathrm{SO}_{4}^{2-}$ 浓度升高的主要原因. 之后, 经过一系列的 $\mathrm{SO}_{2}$ 排放控制措 施, 长江中上游部分地区水体 $\mathrm{SO}_{4}^{2-}$ 浓度变化趋于平稳 ${ }^{[4]}$. 然而, 相比之下, 氮氧化物排放量却持续增加, 对酸 沉降的贡献逐渐增强 ${ }^{[9]}$, 引起地表水体 $\mathrm{NO}_{3}^{-}$浓度增加, 延迟了酸化水体的恢复 ${ }^{[10]}$. 另外, 大气氮沉降输人的 氮营养盐已成为引起湖泊水体富营养化的重要原因之一 ${ }^{[11]}$, 特别是夏秋季节的高水温期, 氮沉降可能会导 致淡水水体富营养化程度加剧 ${ }^{[12]}$, 对饮用水安全产生不利影响, 直接威胁人体健康 ${ }^{[13]}$. 目前, 氮或氮和磷已 经成为我国淡水湖泊初级生产力的主要限制因子 ${ }^{[14]}$, 因此,酸沉降尤其是氮沉降对地表水体酸化和富营养 化的影响尤为重要.

太湖流域位于我国长江三角洲地区, 处于我国长江中下游酸雨区. 随着太湖流域经济的快速发展, $\mathrm{SO}_{2}$ 和氮氧化物的大量排放使得流域酸沉降不断加重 ${ }^{[15]}$, 甚至观测到 $\mathrm{pH}$ 为 3.84 的酸性降水 ${ }^{[12]}$. 降雨中 $\mathrm{SO}_{4}^{2-}$ 当 量浓度最高, 占离子总量的 $48.7 \%$, 其次是 $\mathrm{NO}_{3}^{-}(8.1 \%), \mathrm{SO}_{4}^{2-}$ 和 $\mathrm{NO}_{3}^{-}$是降水中最主要的酸根阴离子 ${ }^{[16]}$. 最近 几十年里, 受强烈的人为活动等因素的影响, 太湖水体水化学特征较过去已发生了明显的转变 ${ }^{[15]}$. 太湖作 为典型的淡水湖泊, 湖水酸根阴离子变化对湖泊酸碱平衡体系及生态环境演变具有重要意义. 目前, 虽然太 湖流域 $\mathrm{SO}_{2}$ 排放有所降低, 但酸雨频率并未显著下降, 太湖流域仍受酸沉降的影响 ${ }^{[15]}$. 这对湖水酸根离子变 化趋势及水环境演变会产生什么影响? 是需要进一步研究的问题.

本文在上述研究的基础上,基于太湖流域几十年以来的降水 $\mathrm{SO}_{4}^{2-}$ 和 $\mathrm{NO}_{3}^{-}$以及湖水 $\mathrm{SO}_{4}^{2-}$ 和 $\mathrm{NO}_{3}^{-}$的数据 资料, 结合流域社会经济数据, 以及湖水水化学和富营养化指标等相关数据分析太湖水体 $\mathrm{SO}_{4}^{2-}$ 和 $\mathrm{NO}_{3}^{-}$长期 变化趋势及其原因, 探讨太湖水体酸根离子变化的环境意义. 本研究一方面可为强烈人为干预条件下的湖 泊流域酸碱平衡体系的研究提供基础资料,另一方面也可以为太湖流域环境综合治理提供理论依据.

\section{1 材料与方法}

\section{1 研究区概况}

太湖是我国第三大淡水湖, 流域面积 $36000 \mathrm{~km}^{2}$, 水域面积为 $2338 \mathrm{~km}^{2} .2016$ 年末储水量 $51.4 \times 10^{8} \mathrm{~m}^{3}$, 多年平均水深 $1.9 \mathrm{~m}$, 属于典型的浅水湖泊. 目前湖水交换周期为 309 天. 太湖流域河网密布,水系发达,人 口众多,多年平均 GDP 约占全国 GDP 总量的 10\%左右 (水利部太湖流域管理局: http ://www.tba.gov.cn/), 是我国经济最发达的地区之一. 同时, 太湖流域也是我国 $\mathrm{SO}_{2}$ 和氮氧化物排放量较高的地区之一, 多年来 (2006- 2012 年) 流域平均降雨 $\mathrm{pH}$ 一直处在 4.39 4.73, 酸雨频率平均高达 $72.5 \%$, 酸沉降已成为太湖流最 严重的环境问题之一 ${ }^{[15]}$.

\section{2 数据来源与采样分析}

太湖流域降雨中酸根离子数据 (1980-2014 年) 主要来自己发表的科技文献 ${ }^{[17]}$. 在文献数据的处理过 程中, 先对文献收集到流域不同地区各年份降雨酸根离子数据进行异常值检验和剔除后得到其年均值, 以 此缩小太湖流域降雨酸根离子时空变化的差异性以及季节变化和降雨强度对酸根离子浓度变化的影响,使 得文献收集的太湖流域酸根离子数据与本研究采样获取的数据在大空间和时间尺度上能够说明太湖流域 酸沉降的客观发展趋势. 近年降雨酸根离子数据由本研究于 2011 年 1 和 11 月,2012 年 11 和 1 月,2015 年 4 和 11 月在太湖西部宜兴市大浦镇 (图 1) 采样分析得出. 太湖水体酸根离子及其他水质指标历史数据分别收 集自长江流域水文统计年鉴 $(1950 s-1970 s)(H Y)$, 全球水质监测系统 (GEMS, 1980s - 1990s) 和中国生态 
系统定位观测与研究数据集 $(2000 \mathrm{~s})(\mathrm{CERN})^{[18]}, 2011-2015$ 年太湖水体酸根离子数据于 2011 年 $6 、 8$ 和 11 月, 2012 年 1 和 11 月, 2014 年 7 和 11 月,2015 年 4 和 11 月采样分析得出. 太湖湖面降雨量数据来源于长江 流域水文统计年鉴, 具体采样点位和监测点见图 1. 流域社会经济数据, 如机动车数量、氮肥施用量、污水排 放量、酸性物质排放量 ( $\mathrm{SO}_{2}$ 和氮氧化物), 大气环境质量等数据来自太湖流域各省市统计年鉴. 所有降雨、湖 水样品均用预先处理好的 $500 \mathrm{ml}$ 聚乙烯塑料瓶采集, 使用哈希水质参数仪 $(\mathrm{HACH})$ 现场测定水质参数 ( $\mathrm{pH}$ 、 电导率、溶解氧等). 每个样品均采集一个平行样, 并于 $0 \sim 4^{\circ} \mathrm{C}$ 冷藏保存带回实验室分析. 水质 $\mathrm{SO}_{4}^{2-}$ 采用铬酸 钡分光光度法 $(\mathrm{HJ} / \mathrm{T} 342-2007), \mathrm{NO}_{3}^{-}$采用酚二磺酸分光光度法 $(\mathrm{GB} 7480-1987)$, 平行样的相对偏差在 $10 \%$ 左右, 水体叶绿素 $\mathrm{a}$ 浓度的测定采用分光光度法 ${ }^{[19]}$.

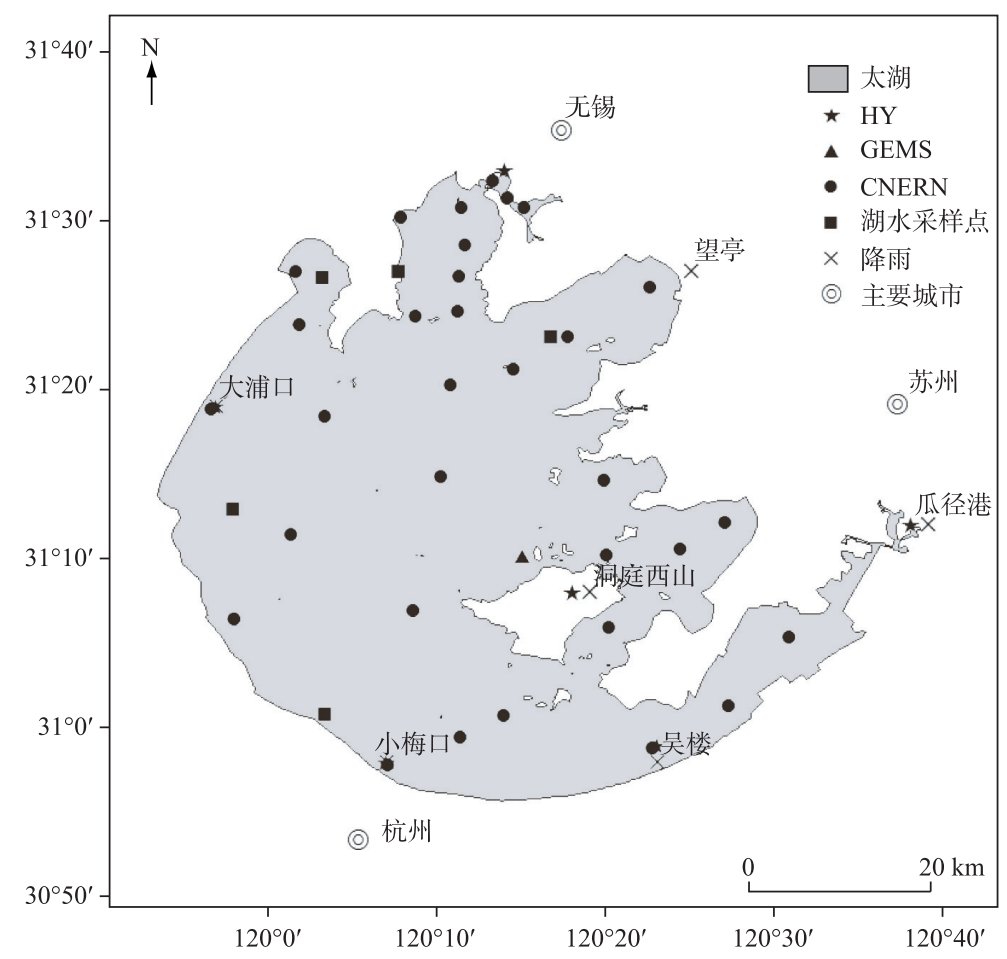

图 1 太湖水化学采样和降雨观测点位

Fig.1 Lake Taihu and sampling sites of lake water chemistry and rainfall gauging station in this study

\section{3 数据计算与处理}

1.3.1 太湖酸根阴离子年平均沉降负荷计算 太湖流域酸根阴离子年平均沉降率可用降雨酸根阴离子浓度 与年降雨量的乘积求得,具体计算公式为:

$$
F_{\mathrm{W}}=K \cdot C_{\mathrm{y}} \cdot R_{\mathrm{y}}
$$

式中, $K$ 为换算系数, $K=1 \mathrm{~L} \cdot \mathrm{kg} /\left(\mathrm{mg} \cdot \mathrm{mm} \cdot \mathrm{km}^{2}\right) ; F_{\mathrm{W}}$ 为年沉降率, $\mathrm{kg} /\left(\mathrm{km}^{2} \cdot \mathrm{a}\right) ; C_{\mathrm{y}}$ 为降雨中酸根阴离子浓度, $\mathrm{mg} / \mathrm{L} ; R_{\mathrm{y}}$ 为年平均降雨量, $\mathrm{mm}$.

由降雨直接输人太湖的酸根阴离子年平均负荷量计算公式为:

$$
F_{\mathrm{L}}=F_{\mathrm{W}} \cdot A \cdot T / 365 / 1000
$$

式中, $F_{\mathrm{L}}$ 为由降雨直接输人太湖的酸根阴离子年平均负荷量, $\mathrm{t} / \mathrm{a} ; A$ 为与太湖水面面积 $\left(2338 \mathrm{~km}^{2}\right), T$ 为太 湖水交换周期 ( $309 \mathrm{~d})$.

1.3.2 Mann-Kendall 突变分析方法 ${ }^{[20]}$ 对具有 $n$ 个样本量的时间序列 $X$,构造一个秩序列:

$$
S_{k}=\sum_{i=1}^{k} r_{i}(k=2,3, \cdots, n)
$$


其中,

$$
r_{i}=\left\{\begin{array}{ll}
+1 & \text { 当 } x_{i}>x_{j} \\
0 & \text { 否则 }
\end{array}\right\}(j=1,2, \cdots, i)
$$

秩序列 $S_{k}$ 是第 $i$ 时刻数值大于 $j$ 时刻数值个数的累计数. 在时间序列上随机独立的假定下, 定义统计量:

$$
U F_{k}=\frac{\left[S_{k}-E\left(S_{k}\right)\right]}{\sqrt{\operatorname{Var}\left(S_{k}\right)}}(k=1,2, \cdots, n)
$$

式中, $U F_{1}=0, E\left(S_{k}\right), \operatorname{Var}\left(S_{k}\right)$ 是累积数 $S_{k}$ 的均值和方差, 在 $x_{1}, x_{2}, x_{3}, \cdots, x_{n}$ 相互独立, 且具有连续相同分 布时, $E\left(S_{k}\right)$ 和 $\operatorname{Var}\left(S_{k}\right)$ 可由下式计算:

$$
\begin{gathered}
E\left(S_{k}\right)=n(n+1) / 4 \\
\operatorname{Var}\left(S_{k}\right)=n(n-1)(2 n+5) / 72
\end{gathered}
$$

$U F_{k}$ 系列为标准正态分布, 它是按照时间序列 $x$ 顺序 $x_{1}, x_{2}, \cdots, x_{n}$ 计算出来的统计量序列, 给定显著性 水平 $a$, 对应正态分布表, 若 $|U F i|>U_{a}$, 则表明序列存在明显的趋势变化. 按照时间序列 $x$ 逆序列, $x_{n}$, $x_{n-1}, \cdots, x_{1}$, 再重复上述过程, 同时使 $U B_{k}=-U F_{k}, k=n, n-1, \cdots, 1, U B_{1}=0$, 并分析绘出的 $U F_{k}$ 和 $U B_{k}$ 曲线图. 若统计量 $U F_{k}$ 或 $U B_{k}$ 的值大于 0 , 则表明序列呈上升趋势, 小于 0 则表明呈下降趋势. 若 $U F_{k}$ 和 $U B_{k}$ 曲线超过 临界线 ( $\alpha=0.05$ 的显著性水平), 且在临界线 $U_{0.05}= \pm 1.96$ 之间有交点, 那么交点对应的时刻便是突变开始 的时间.

本研究选择 Mann-Kendall 趋势检验和突变点分析方法研究太湖流域降雨和湖水酸根阴离子长期变化 趋势 ${ }^{[20]}$, 并用 Sen's 斜率估计法 ${ }^{[21]}$ 计算酸根阴离子变化趋势的斜率 $\beta$. 运用 SPSS 23.0 软件对数据进行均 值、标准差等统计分析. 在正态检验的基础上选择合适的统计方法. 显著性水平选择 0.05. 采用 ArcGIS 10.0 与 Origin 9.0 进行绘图.

\section{2 结果与讨论}

\section{1 太湖流域大气降水中酸根离子长期变化趋势及原因}

太湖流域降雨 $\mathrm{SO}_{4}^{2-}$ 和 $\mathrm{NO}_{3}^{-}$浓度长期变化趋势如图 2 所示. 30 多年来, 太湖流域降雨中 $\mathrm{SO}_{4}^{2-}$ 浓度总体上 呈显著下降趋势 $(P<0.01)$, 年平均下降率为 $0.28 \mathrm{mg} /(\mathrm{L} \cdot \mathrm{a})$ ( 图 2a) ; $\mathrm{NO}_{3}^{-}$浓度却呈显著上升趋势 $(P<$ 0.01 ), 年平均增长率为 $0.05 \mathrm{mg} /(\mathrm{L} \cdot \mathrm{a})$ ( 图 $2 \mathrm{~b}$ ).

Mann-Kendall 突变分析表明: 降雨 $\mathrm{SO}_{4}^{2-}$ 浓度 UF-UB 曲线在 2006- 2007 年之间发生了突变,并且降雨 $\mathrm{SO}_{4}^{2-}$ 浓度的 UF 值小于-1.96, 突破了 $\alpha=0.05$ 的临界值区域 (图 2c). 流域降雨 $\mathrm{SO}_{4}^{2-}$ 浓度变化大致经历了两 个阶段:第 1 阶段 (2006 年以前), 降雨 $\mathrm{SO}_{4}^{2-}$ 浓度虽有所下降, 但波动较大 $(11.03 \pm 3.35 \mathrm{mg} / \mathrm{L})$; 第 2 阶段 ( 2007 年至今), 降雨 $\mathrm{SO}_{4}^{2-}$ 浓度仅为 $5.20 \pm 0.53 \mathrm{mg} / \mathrm{L}$, 较 2006 年以前相比, 下降了 1.12 倍, 下降最为显著. 与 $\mathrm{SO}_{4}^{2-}$ 浓度变化趋势不同, 降雨 $\mathrm{NO}_{3}^{-}$浓度 UF-UB 曲线在 1994-1995 年之间发生了突变 (图 2d), 流域降雨 $\mathrm{NO}_{3}^{-}$浓度变化大致经历了两个阶段. 第 1 阶段 (1995 年以前), 降雨 $\mathrm{NO}_{3}^{-}$浓度变化波动较大, 平均浓度仅为 $1.53 \pm 0.60 \mathrm{mg} / \mathrm{L}$; 第 2 阶段 (1996 年至今), 降雨 $\mathrm{NO}_{3}^{-}$浓度显著增长 $(2.59 \pm 0.33 \mathrm{mg} / \mathrm{L})$. 太湖流域降雨 $\mathrm{SO}_{4}^{2-}$ 和 $\mathrm{NO}_{3}^{-}$浓度长期变化趋势表明: 随着 $\mathrm{SO}_{2}$ 排放控制措施的实施和能源结构的调整 ${ }^{[22]}$, 流域 $\mathrm{SO}_{2}$ 减排取得了显著 成效, 但氮氧化物排放对酸沉降的贡献却呈增加趋势 ${ }^{[4]}$. 因此, 流域降雨 $\mathrm{SO}_{4}^{2-}$ 浓度呈显著下降趋势, 而 $\mathrm{NO}_{3}^{-}$ 浓度呈显著升高趋势.

$\mathrm{SO}_{4}^{2-} / \mathrm{NO}_{3}^{-}$的当量比是分析酸性降水类型的重要数据. 一般认为: $\mathrm{SO}_{4}^{2-} / \mathrm{NO}_{3}^{-}$当量比大于 1 , 属于硫酸型 雨; 当量比小于 1 , 为硝酸型酸雨 ${ }^{[23]} .30$ 多年来, 太湖流域酸性降雨 $\mathrm{SO}_{4}^{2-} / \mathrm{NO}_{3}^{-}$显著下降 $(P<0.01)$ (图 $3 \mathrm{a}$ ), 表明 $\mathrm{SO}_{4}^{2-}$ 对降雨酸度的贡献逐渐下降, $\mathrm{NO}_{3}^{-}$对降雨酸度的贡献逐渐增强. 相关分析表明: 降雨 $\mathrm{SO}_{4}^{2-}$ 浓度与流 域 $\mathrm{SO}_{2}$ 排放量显著相关 $(r=0.62, P<0.01)$ (图 4a), $\mathrm{NO}_{3}^{-}$浓度与流域机动车保有量显著相关 $(r=0.75, P<$ 0.01 ) (图 4b). 进一步说明: 太湖流域酸沉降并未因 $\mathrm{SO}_{2}$ 排放量下降而有显著改善, 与氮氧化物排放量升高 有关, 日益严重的氮沉降对太湖流域水环境的影响需得到重视.

\section{2 太湖湖水中酸根离子长期变化趋势}

太湖水体 $\mathrm{SO}_{4}^{2-}$ 和 $\mathrm{NO}_{3}^{-}$浓度长期变化趋势见图 5, 与流域降雨 $\mathrm{SO}_{4}^{2-}$ 和 $\mathrm{NO}_{3}^{-}$浓度长期变化趋势相反, 60 多 

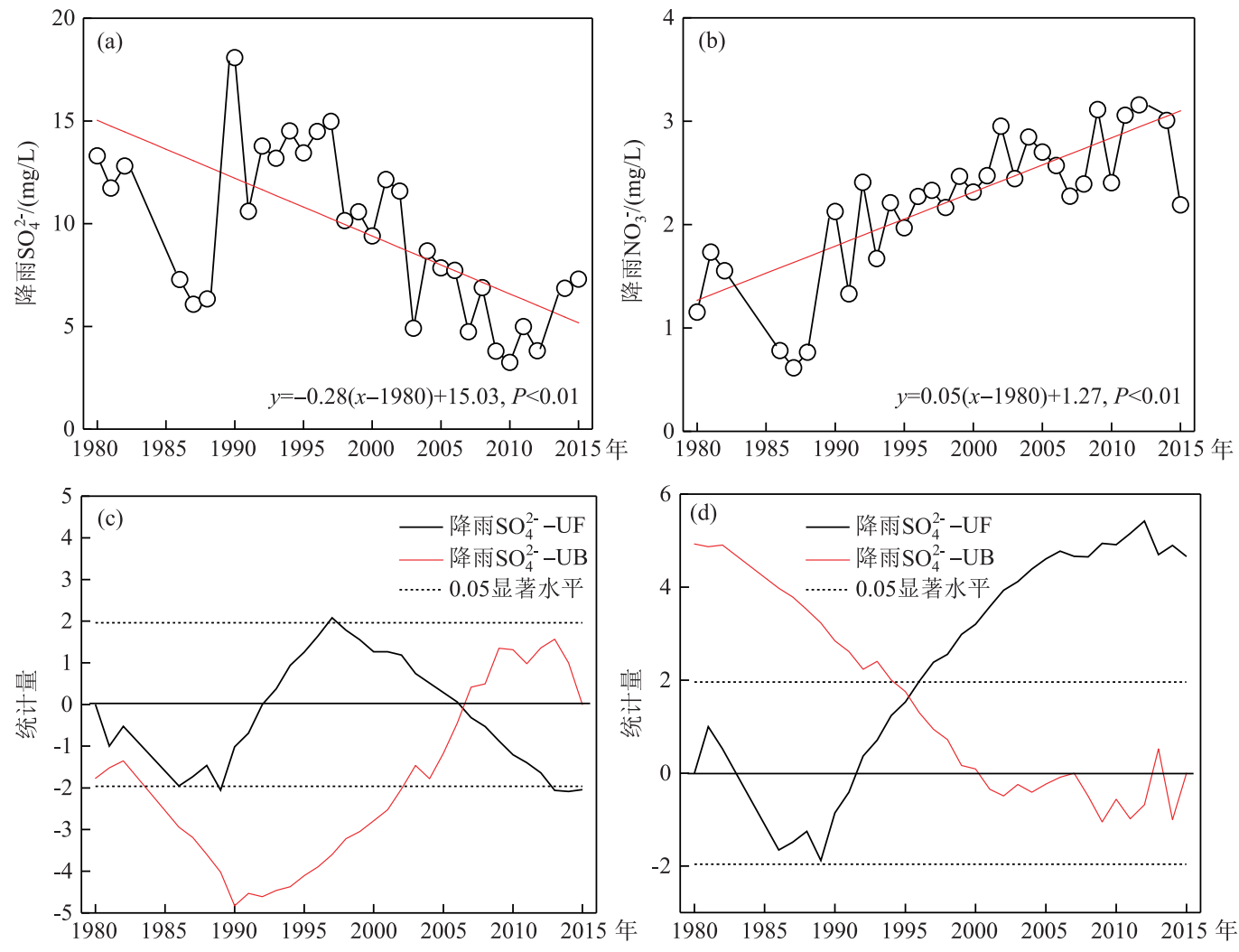

图 2 太湖流域降雨 $\mathrm{SO}_{4}^{2-}$ 和 $\mathrm{NO}_{3}^{-}$浓度长期变化趋势 $(\mathrm{a} 、 \mathrm{~b})$ 及其突变分析 $(\mathrm{c} 、 \mathrm{~d})$

Fig. 2 Long-term trends ( a, b) and mutation analysis (c, d) of $\mathrm{SO}_{4}^{2-}$ and $\mathrm{NO}_{3}^{-}$concentrations in the rain water in Lake Taihu watershed
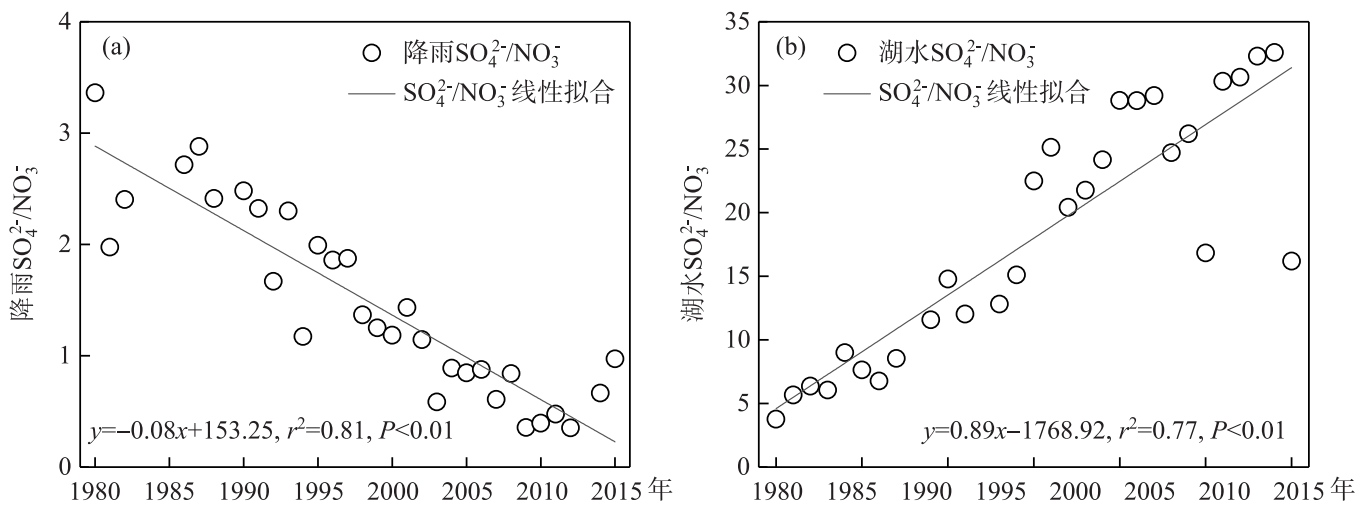

图 3 太湖流域降雨 $(\mathrm{a})$ 和湖水 $(\mathrm{b}) \mathrm{SO}_{4}^{2-} / \mathrm{NO}_{3}^{-}$当量比变化趋势

Fig.3 Trends of $\mathrm{SO}_{4}^{2-} / \mathrm{NO}_{3}^{-}$ratio in the rain water (a) and lake water (b) in Lake Taihu watershed

年来, 太湖水体 $\mathrm{SO}_{4}^{2-}$ 呈显著上升趋势 $(P<0.01)$, 年平均增长率为 $1.24 \mathrm{mg} /(\mathrm{L} \cdot \mathrm{a})($ 图 $5 \mathrm{a})$; $\mathrm{NO}_{3}^{-}$浓度却呈显 著下降趋势 $(P<0.01)$, 年平均下降率为 $0.02 \mathrm{mg} /(\mathrm{L} \cdot \mathrm{a})$ (图 $5 \mathrm{~b})$.

Mann-Kendall 突变分析表明: 湖水 $\mathrm{SO}_{4}^{2-}$ 浓度 UF-UB 曲线在 1994-1995 年之间发生了突变 (图 5c); 

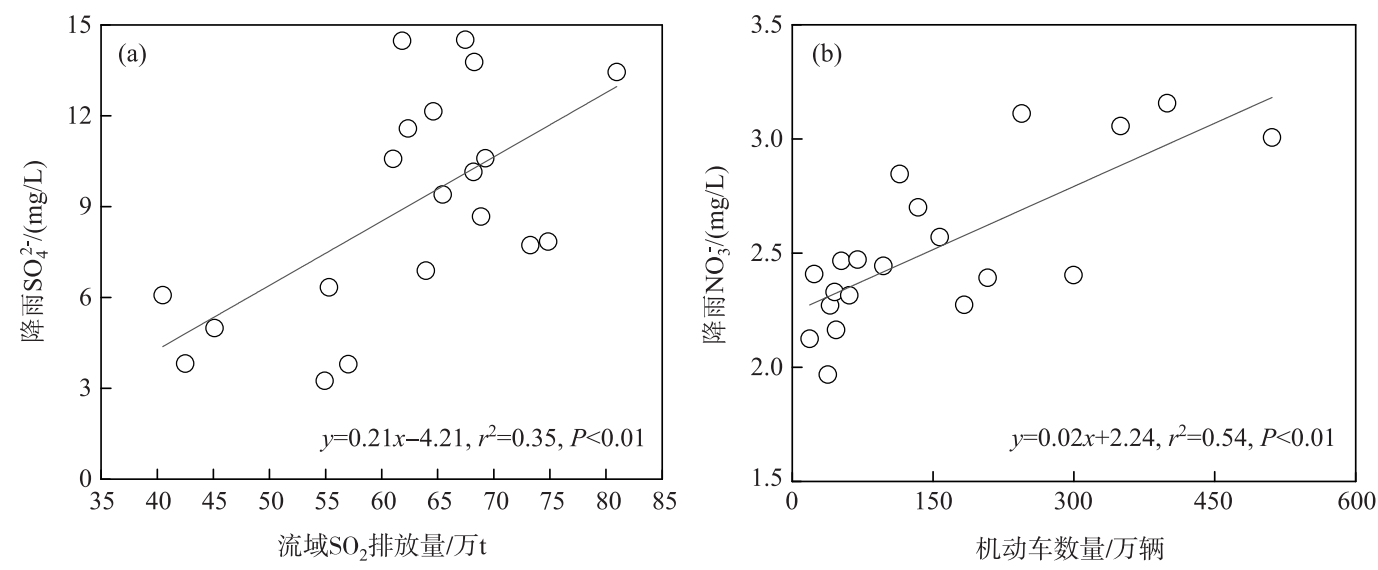

图 4 太湖流域降雨 $\mathrm{SO}_{4}^{2-}(\mathrm{a})$ 和 $\mathrm{NO}_{3}^{-}(\mathrm{b})$ 浓度与流域社会经济变量的关系

Fig.4 Correlation between $\mathrm{SO}_{4}^{2-}(\mathrm{a})$ and $\mathrm{NO}_{3}^{-}(\mathrm{b})$ concentrations

in the rain water and socioeconomic variables in the Lake Taihu watershed

$\mathrm{NO}_{3}^{-}$浓度 UF-UB 曲线在 1999-2000 年、2002-2003 年和 2005-2006 年发生了 3 次突变 (图 5d). 总体来 看, 太湖水体 $\mathrm{SO}_{4}^{2-}$ 浓度变化大致经历了 3 个阶段: 第 1 阶段 (1994 年以前), 湖水 $\mathrm{SO}_{4}^{2-}$ 浓度增长缓慢 $(25.75 \pm$ $12.29 \mathrm{mg} / \mathrm{L}$ ), 处于初期增长阶段; 第 2 阶段 (1995-2006 年), 湖水 $\mathrm{SO}_{4}^{2-}$ 浓度增长最快 $(67.39 \pm 19.44 \mathrm{mg} / \mathrm{L})$, 处于快速增长阶段. 较 1994 年以前相比, 仅 12 年时间, 湖水 $\mathrm{SO}_{4}^{2-}$ 浓度就升高了 1.64 倍; 第 3 阶段 (2007 年 至今), 湖水 $\mathrm{SO}_{4}^{2-}$ 浓度增长缓慢 $(71.99 \pm 10.70 \mathrm{mg} / \mathrm{L})$, 处于恢复阶段, 与降水 $\mathrm{SO}_{4}^{2-}$ 浓度变化趋势基本一致. 这 主要是因为流域能源结构方式的改变, 并且 $\mathrm{SO}_{2}$ 排放得到有效控制, 大气酸沉降对湖水 $\mathrm{SO}_{4}^{2-}$ 浓度增长的贡献 逐渐下降 ${ }^{[15]}$. 湖水 $\mathrm{NO}_{3}^{-}$浓度变化也大致经历了 3 个阶段: 第 1 阶段 (1999 年之前) 不稳定阶段,湖水 $\mathrm{NO}_{3}^{-}$浓 度较高 $(1.13 \pm 0.21 \mathrm{mg} / \mathrm{L})$, 达到 $\mathrm{I}$ 类水质标准; 第 2 阶段 $\left(2000-2006\right.$ 年), 湖水 $\mathrm{NO}_{3}^{-}$浓度有所下降 $(0.94 \pm 0$. $15 \mathrm{mg} / \mathrm{L}$ ), 但波动较大; 第 3 阶段 (2007 年至今), 湖水 $\mathrm{NO}_{3}^{-}$浓度继续下降 $(0.83 \pm 0.17 \mathrm{mg} / \mathrm{L})$, 达到 III 类水质 标准,这说明太湖流域水污染治理取得了一定的成效.

与降雨 $\mathrm{SO}_{4}^{2-} / \mathrm{NO}_{3}^{-}$的当量比变化不同, 湖水 $\mathrm{SO}_{4}^{2-} / \mathrm{NO}_{3}^{-}$比值不断升高 (图 $3 \mathrm{~b}$ ), 远高于降雨 $\mathrm{SO}_{4}^{2-} / \mathrm{NO}_{3}^{-}$比 值(图 3a), 过量的 $\mathrm{NO}_{3}^{-}$通过反硝化和藻类同化吸收而被去除 ${ }^{[24-25]}$. 因此, 湖水 $\mathrm{NO}_{3}^{-}$浓度受酸沉降影响较 小, 并未呈现升高的趋势, 很好地解释了湖水 $\mathrm{SO}_{4}^{2-} / \mathrm{NO}_{3}^{-}$比值不断升高的原因. 已有研究表明: 大气氮沉降可 以引起地表水体 $\mathrm{NO}_{3}^{-}$浓度升高、 $\mathrm{pH}$ 降低 ${ }^{[26]}$. 近年来, 长江上游部分弱酸化水体并未因 $\mathrm{SO}_{2}$ 排放量下降而显 著改善, 主要原因就是氮氧化物排放量的增长产生更多的 $\mathrm{NO}_{3}^{-}$作为强酸根离子进人水体, 延迟了酸化水体 恢复速率 ${ }^{[4,9]}$. 虽然目前太湖水体并未因流域氮氧化物排放量的增长 $\mathrm{NO}_{3}^{-}$浓度有所升高或者 $\mathrm{pH}$ 有所降低, 但若不加以控制, 未来氮沉降输人的 $\mathrm{NO}_{3}^{-}$过饱和将会导致流域更多 $\mathrm{NO}_{3}^{-}$的浸出以及阳离子的损耗, 必然会 对湖水酸碱平衡体系产生重要影响.

\section{3 太湖水体酸根离子主要来源}

自然条件下, 水体 $\mathrm{SO}_{4}^{2-}$ 主要来源于蒸发岩的溶解, 易受人为活动的影响 ${ }^{[27]}$. 随着流域社会经济的快速 发展, 太湖水化学变化已经从最初的以自然风化为主导转变为以人类活动为主导 ${ }^{[15]}$. 太湖流域碳酸盐岩丰 富, 属于酸不敏感地区, 长期以来, 酸沉降加速了流域碳酸盐岩的风化, 导致大量 $\mathrm{Ca}$ 和 $\mathrm{Mg}$ 溶蚀进入水 体 ${ }^{[17,28]}$. 从湖水 $\mathrm{SO}_{4}^{2-}$ 浓度突变时间点来看, 1994 年以前, 湖水 $\mathrm{SO}_{4}^{2-}$ 虽处于缓慢增长期, 但与湖水 $\mathrm{Ca}^{2+}+\mathrm{Mg}^{2+}$ 浓度变化基本不相关 (图 6a). 这说明: 在未受强烈的酸沉降影响下, 湖水 $\mathrm{SO}_{4}^{2-}$ 浓度变化主要受流域蒸发岩 影响. 1995 年至今, 受流域酸沉降影响, 湖水 $\mathrm{SO}_{4}^{2-}$ 与 $\mathrm{Ca}^{2+}+\mathrm{Mg}^{2}$ 显著相关 $(r=0.63, P<0.05$ ) (图 6a). 按照公 式(1) 的计算结果: 目前 (2011-2015 年), 即使流域 $\mathrm{SO}_{2}$ 得到了有效控制 (图 6b), 流域降雨 $\mathrm{SO}_{4}^{2-}$ 沉降率仍高 达 $2295.16 \mathrm{~kg} \mathrm{~S} /\left(\mathrm{km}^{2} \cdot \mathrm{a}\right)$, 远高于 $1970 \mathrm{~s}-1980 \mathrm{~s}$ 加拿大 Ontario 酸化湖泊所在区域大气 $\mathrm{SO}_{4}^{2-}$ 沉降率 $(720 \sim$ 

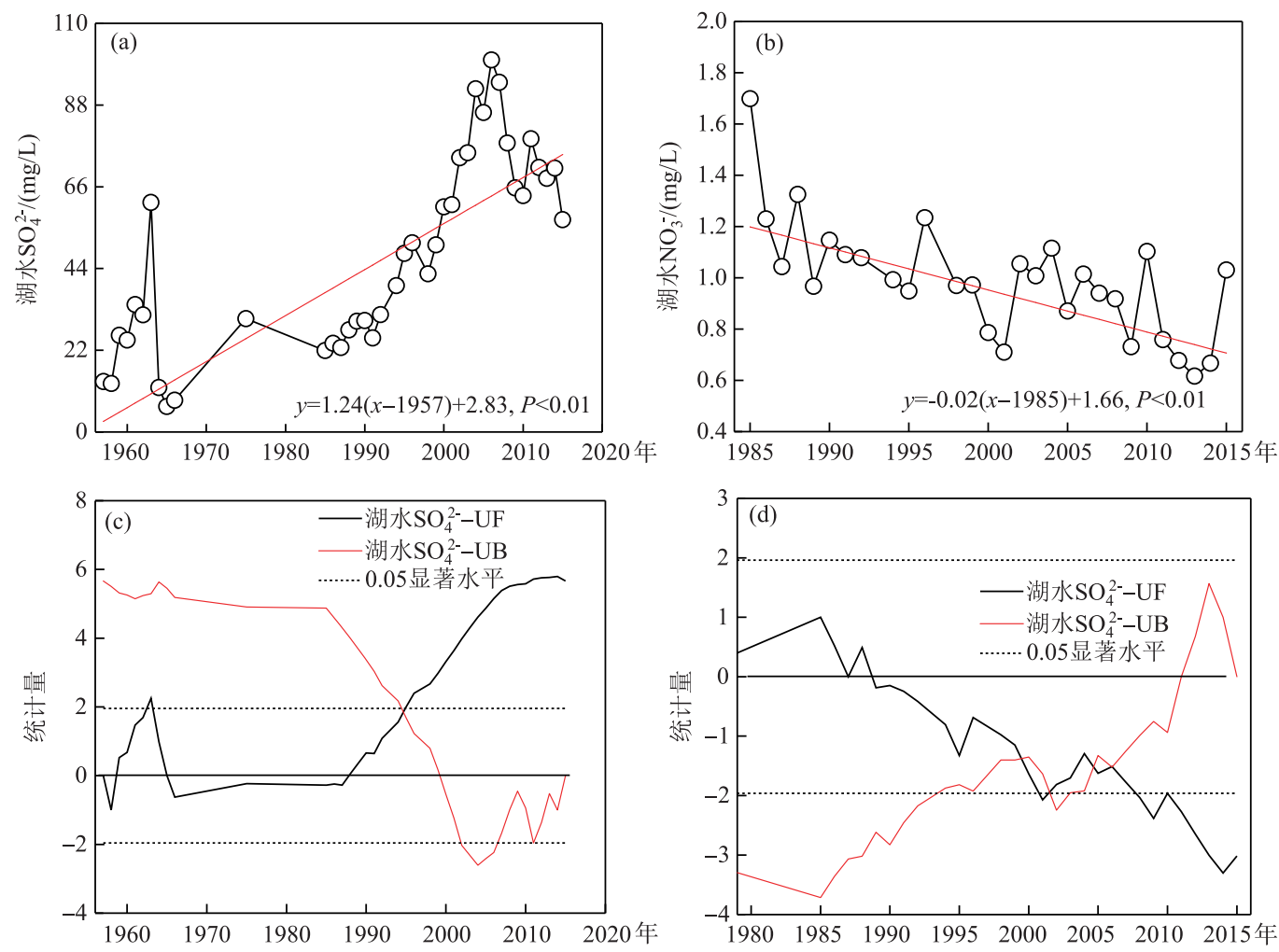

图 5 太湖水体 $\mathrm{SO}_{4}^{2-}$ 和 $\mathrm{NO}_{3}^{-}$浓度长期变化趋势 $(\mathrm{a} 、 \mathrm{~b})$ 及其突变分析 $(\mathrm{c} 、 \mathrm{~d})$

Fig.5 Long-term trends ( a, b) and mutation analysis (c, d) of $\mathrm{SO}_{4}^{2-}$ and $\mathrm{NO}_{3}^{-}$concentrations in the Lake Taihu water

$\left.1250 \mathrm{~kg} \mathrm{~S} /\left(\mathrm{km}^{2} \cdot \mathrm{a}\right)\right)^{[29]}$. 已有研究表明: 大气 $\mathrm{SO}_{4}^{2-}$ 高负荷沉降会引起流域土壤 $\mathrm{SO}_{4}^{2-}$ 的过饱和, 使得 $\mathrm{SO}_{4}^{2-}$ 不 断浸出, 且酸性条件下更容易促进土壤的 $\mathrm{SO}_{4}^{2-}$ 浸出并随径流进入水体, 导致地表水体 $\mathrm{SO}_{4}^{2-}$ 浓度升高 ${ }^{[30]}$. 目 前太湖流域降水 $\mathrm{SO}_{4}^{2-}$ 浓度虽呈下降趋势( 图 2a), 但受酸沉降长期影响, 流域土壤可能对 $\mathrm{SO}_{4}^{2-}$ 吸附处于过饱 和状态, 导致 $\mathrm{SO}_{4}^{2-}$ 不断随降雨径流进人水体. 因此, 长期以来湖水 $\mathrm{SO}_{4}^{2-}$ 浓度呈显著升高的趋势 (图 5a). 在自 然条件下, 太湖 $\mathrm{SO}_{4}^{2-}$ 浓度变化受蒸发岩影响较小 ${ }^{[15]}$, 湖水 $\mathrm{SO}_{4}^{2-}$ 浓度变化亦受流域污水排放影响较小 ${ }^{[27]}$; 此 外,太湖水体 $\mathrm{SO}_{4}^{2-}$ 浓度远高于同时期鄱阳湖水体 $\mathrm{SO}_{4}^{2-}$ 浓度 ${ }^{[31-32]}$, 且太湖湖水 $\mathrm{SO}_{4}^{2-}$ 浓度与流域降雨 $\mathrm{pH}$ 呈显 著负相关 ${ }^{[15]}$, 这很好地说明了区域 $\mathrm{SO}_{2}$ 排放是湖水 $\mathrm{SO}_{4}^{2-}$ 浓度升高的重要原因. 此外, 由于流域硫化物排放控 制措施, 自 2006 年来流域 $\mathrm{SO}_{2}$ 排放量呈降低趋势 (图 6b). 因此, 与 $2000 \mathrm{~s}$ 太湖水体 $\mathrm{SO}_{4}^{2-}$ 浓度 $(79.27 \pm 28.55$ $\mathrm{mg} / \mathrm{L})$ 相比, 目前太湖水体 $\mathrm{SO}_{4}^{2-}$ 浓度 $(69.97 \pm 19.12 \mathrm{mg} / \mathrm{L})$ 已有显著降低 $(P<0.05)$, 这也说明水体 $\mathrm{SO}_{4}^{2-}$ 浓度 对流域硫化物排放具有明确的响应关系.

太湖水体富营养化程度与人类活动密切相关 ${ }^{[33]}$. Wang 等 ${ }^{[34]}$ 的研究表明: 太湖水体氮主要来源于农业 非点源排放,农业非点源污染曾占太湖水体氮污染物负荷总量的 77\% 左右. 但自 1999 年之后, 太湖流域氮 肥使用量明显下降 (图 7a), 对湖水 $\mathrm{NO}_{3}^{-}$浓度下降有显著的贡献. 但随着机动车保有量逐年升高 (图 7a), 机 动车尾气氮氧化物排放对大气氮沉降的贡献也逐步增强, 导致太湖流域酸沉降并未因 $\mathrm{SO}_{2}$ 排放而明显改善, 酸雨频率处于较高水平 (图 6b). 加之太湖流域人口的不断增长, 用水量不断加大 ${ }^{[35]}$, 特别是生活污水排放 呈显著增长的趋势 (图 6b), 污水排放对湖水氮污染物负荷的贡献也升高. 计算显示: 由大气降雨直接输人 到太湖水体的 $\mathrm{NO}_{3}^{-}$年平均负荷量高达 $5824.12 \mathrm{t} \mathrm{N} / \mathrm{a}$ ( 2011 年), 占同时期外界氮人湖总量 ${ }^{[36]}$ ( 2011 年: 
$58845 \mathrm{t})$ 的 9.9\%. 此外, 流域农业源 TN 排放总量达 $10190 \mathrm{t} \mathrm{N} / \mathrm{a}^{[37]}$, 占同时期外界人湖总量的 $17.4 \%$. 考虑到 太湖流域生活污水排放量逐年升高, 工业污水排放量自 2006 年后基本呈下降趋势 (图 7b), 因此可以认为: 目前太湖水体 $\mathrm{NO}_{3}^{-}$主要来源于生活污水排放, 其次是流域农业非点源污染以及工业废水排放和大气降水输 人. 这与最近的用同位素研究太湖氮负荷来源的结果基本一致 ${ }^{[25]}$.
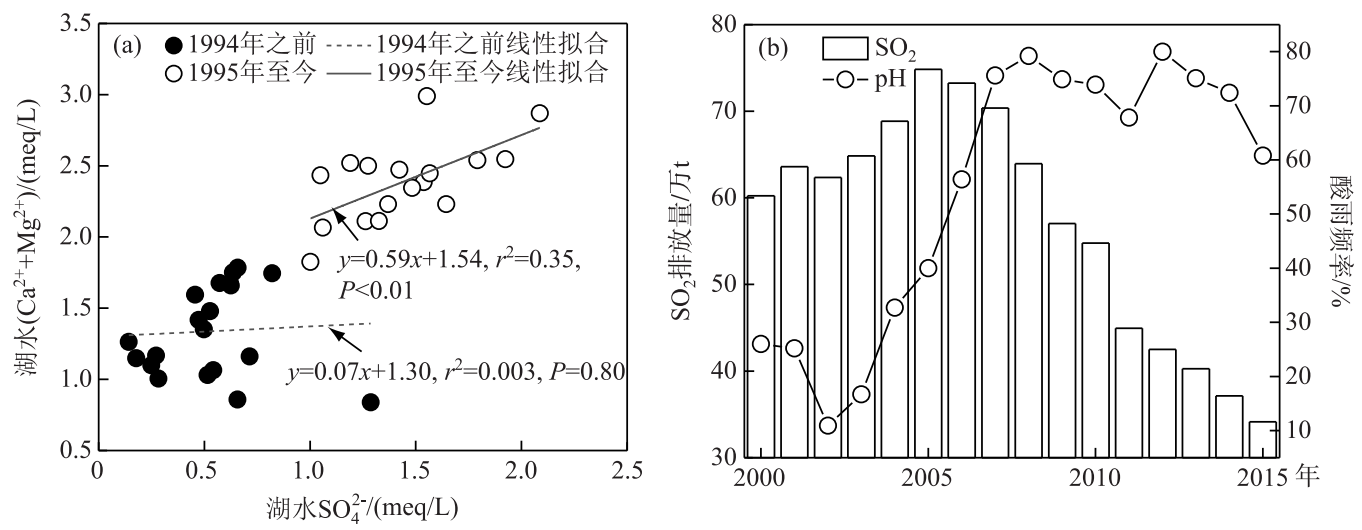

图 6 太湖水体 $\mathrm{SO}_{4}^{2-}$ 与 $\mathrm{Ca}^{2+}+\mathrm{Mg}^{2+}$ 相关性 (a) 和太湖流域 $\mathrm{SO}_{2}$ 排放量与酸雨频率 $(\mathrm{b})$

Fig. 6 Correlation between $\mathrm{SO}_{4}^{2-}$ and $\mathrm{Ca}^{2+}+\mathrm{Mg}^{2+}$ in Lake Taihu water (a) and

$\mathrm{SO}_{2}$ emissions and acid rain frequency in Lake Taihu watershed (b)
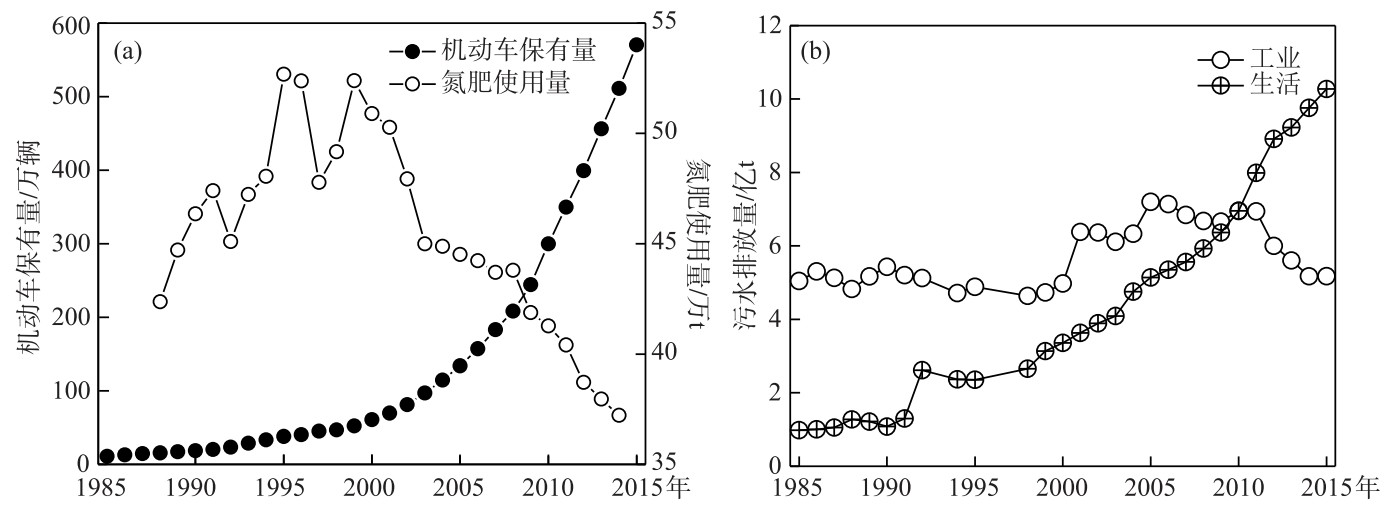

图 7 氮肥使用量和机动车保有量 $(\mathrm{a})$ 与流域污水排放 $(\mathrm{b})$

Fig.7 N fertilizer application and vehicle numbers (a) and waste water discharge in Lake Taihu watershed (b)

\section{4 酸根离子变化对太湖水环境的影响}

受区域酸沉降的长期影响, 目前太湖水体 $\mathrm{SO}_{4}^{2-}$ 浓度及总硬度 $\left(\mathrm{Ca}^{2+}\right.$ 和 $\left.\mathrm{Mg}^{2+}\right)$ 均有明显增高趋势 ${ }^{[15,38]}$. 大 量研究表明:氮氧化物排放量的增加, 加剧了流域阳离子的流失, 滞后了酸化水体的恢复过程 ${ }^{[4,26]}$. 目前, 太 湖流域氮氧化物排放对区域酸沉降的贡献逐步增强, 此外, 区域酸沉降的加剧, 会严重扰乱的生态系统结构 和功能, 甚至可能改变土壤缓冲能力 ${ }^{[39]}$, 导致土壤酸化. 虽然太湖水体并未因酸沉降的加剧而 $\mathrm{pH}$ 有所下 降,但是酸沉降已经引起了流域阳离子的流失 (主要是 $\mathrm{Ca}^{2+}$ 和 $\left.\mathrm{Mg}^{2+}\right)^{[17]}$. 因此,太湖流域降雨 $\mathrm{NO}_{3}^{-}$浓度升 高, 必然会对流域生态系统产生不利影响. $Y u$ 等 ${ }^{[17]}$ 的研究表明:如果目前的酸沉降强度持续,太湖流域主要 阳离子将会在 $2040 \mathrm{~s}$ 初消耗殆尽而失去对酸沉降的中和能力,太湖水体也将面临酸化的风险.

另外, 根据 Gerrit 等对 North Sea 大气氮沉降和海水初级生产力的观测结果可知: 大气氮沉降负荷与浮 游植物生物量之间存在明显的量化关系, 即大气氮沉降负荷可促进浮游植物生物量的增加 ${ }^{[40]}$, 且 $\mathrm{NO}_{3}^{-}$作为 
溶解性总氮的重要成分, 可被浮游植物直接利用, 对藻类生长有促进作用 ${ }^{[41]}$. 考虑到太湖平均水深 $1.9 \mathrm{~m}$, 是 个典型的浅水湖泊,光照较强, 尤其是夏秋季节, 表层水体水温较高, $\mathrm{NO}_{3}^{-}$沉降更有利于浮游植物光和作用 的进行和初级生产力的提高 ${ }^{[42]}$. 此外, 太湖又是个典型的吞吐型湖泊, 主要依靠流域大气降水补给, 加之流 域降雨 $\mathrm{NO}_{3}^{-}$浓度呈升高趋势, 因此, 降雨 $\mathrm{NO}_{3}^{-}$的输人很可能导致太湖浮游植物生物量的增加. 已有文 献 ${ }^{[11,36]}$ 研究表明: 太湖流域大气酸沉降对于太湖的富营养化有重要影响, 本研究的数据也支持这一结论. 图 8 表明: 太湖流域降水 $\mathrm{NO}_{3}^{-}$(图 8a) 和 $\mathrm{NO}_{3}^{-}$沉降通量 (图 8b) 均与湖水叶绿素 a 浓度呈显著正相关, 即降雨 $\mathrm{NO}_{3}^{-}$浓度越高或者 $\mathrm{NO}_{3}^{-}$沉降通量越大, 湖水叶绿素 a 浓度越高. 由此可见, 虽然流域氮氧化物排放并未引起 湖水 $\mathrm{NO}_{3}^{-}$浓度的显著增长, 但降雨输人的 $\mathrm{NO}_{3}^{-}$对太湖初级生产力和富营养化有着重要影响. 因此, 太湖流 域酸沉降对太湖水体酸碱平衡演变和富营养化的贡献不容忽视.
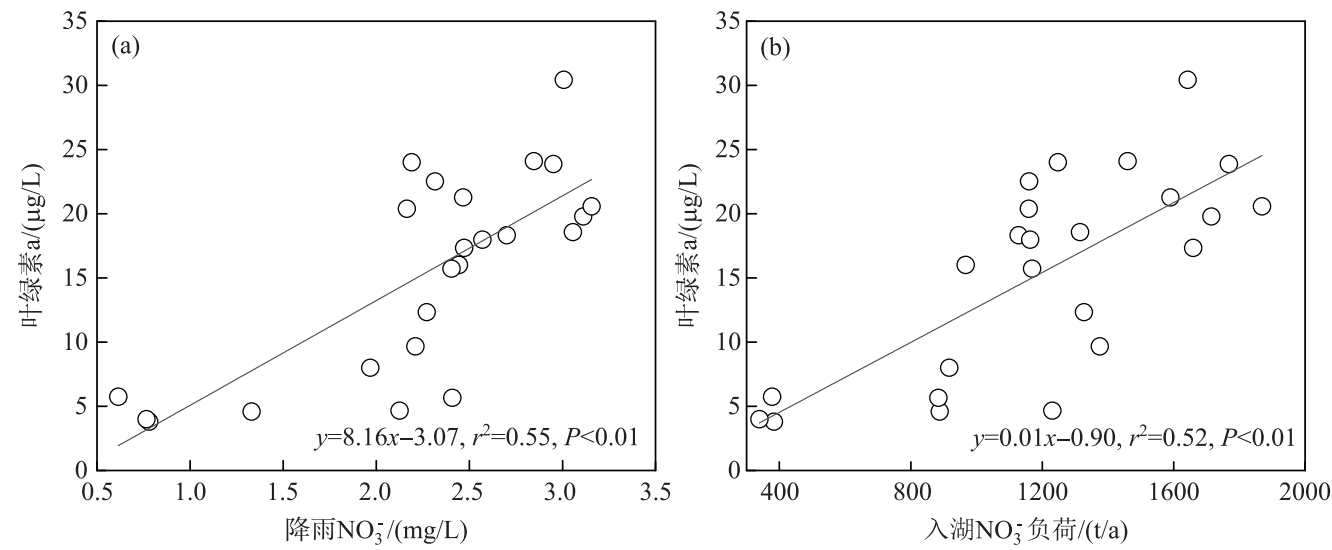

图 8 太湖水体叶绿素 $\mathrm{a}$ 浓度与降水 $\mathrm{NO}_{3}^{-}(\mathrm{a})$ 和降水直接输人太湖的 $\mathrm{NO}_{3}^{-}$负荷 $(\mathrm{b})$ 之间的关系

Fig.8 Relations between Lake Taihu water chlorophyll-a and rain water $\mathrm{NO}_{3}^{-}(\mathrm{a})$, rain water $\mathrm{NO}_{3}^{-}$load (b)

\section{3 结论}

1) 太湖流域降雨 $\mathrm{SO}_{4}^{2-}$ 呈显著下降趋势, 年平均下降率为 $0.28 \mathrm{mg} /(\mathrm{L} \cdot \mathrm{a}) ; \mathrm{NO}_{3}^{-}$浓度却呈显著上升趋势, 年平均增长率为 $0.05 \mathrm{mg} /(\mathrm{L} \cdot \mathrm{a})$; 而湖水 $\mathrm{SO}_{4}^{2-}$ 呈显著上升趋势, 年平均增长率为 $1.24 \mathrm{mg} /(\mathrm{L} \cdot \mathrm{a}) ; \mathrm{NO}_{3}^{-}$浓度却 呈显著下降趋势, 年平均下降率为 $0.02 \mathrm{mg} /(\mathrm{L} \cdot \mathrm{a})$.

2) 太湖水体 $\mathrm{SO}_{4}^{2-} / \mathrm{NO}_{3}^{-}$比值不断升高, 远高于降雨 $\mathrm{SO}_{4}^{2-} / \mathrm{NO}_{3}^{-}$比值, 流域大气 $\mathrm{SO}_{2}$ 排放是湖水 $\mathrm{SO}_{4}^{2-}$ 浓度 增长的重要原因,但氮氧化物排放并未引起湖水 $\mathrm{NO}_{3}^{-}$浓度升高, 说明流域对大气沉降氮有明显的滞留作用.

3) 太湖流域降水 $\mathrm{NO}_{3}^{-}$对于太湖水体初级生产力和富营养化有显著影响,综合控制流域酸沉降对太湖水 体酸碱平衡和富营养化控制具有重要意义.

\section{4 参考文献}

[ 1 ] Baker LA, Herlihy AT, Kaufmann PR et al. Acidic lakes and streams in the United States: The role of acidic deposition. Science, 1991, 252(5009): 1151-1154.

[ 2 ] Eshleman KN, Kaufmann PR. Assessing the regional effects of sulfur deposition on surface water chemistry: the Southern Blue Ridge. Environmental Science \& Technology, 1988, 22(6) : 685-690.

[ 3 ] Lawrence GB, Hazlett PW, Fernandez IJ et al. Declining acidic deposition begins reversal of forest-soil acidification in the northeastern US and eastern Canada. Environmental Science \& Technology, 2015, 49(22) : 13103-13111.

[ 4 ] Duan L, Ma X, Larssen T et al. Response of surface water acidification in upper Yangtze River to $\mathrm{SO}_{2}$ emissions abatement in China. Environmental Science \& Technology, 2011, 45(8) : 3275-3281.

[ 5 ] Hesthagen T, Fjellheim A, Schartau AK et al. Chemical and biological recovery of Lake Saudlandsvatn, a formerly highly 
acidified lake in southernmost Norway, in response to decreased acid deposition. Science of the Total Environment, 2011, 409( 15$)$ : 2908-2916.

[ 6 ] Zhao D, Sun B. Air pollution and acid rain in China. Ambio, 1986, 15(1): 2-5.

[ 7 ] Larssen T, Carmichael GR. Acid rain and acidification in China: the importance of base cation deposition. Environmental Pollution, 2000, 110(1): 89-102.

[ 8 ] Chen JS, Wang FY, Xia XH et al. Major element chemistry of the Changjiang ( Yangtze River). Chemical Geology, 2002, 187(3/4) : 231-255.

[ 9 ] Zhao Y, Duan L, Xing J et al. Soil acidification in China: Is controlling $\mathrm{SO}_{2}$ emissions enough? Environmental Science \& Technology, 2009, 43(21): 8021-8026.

[10] Rosfjord CH, Webster KE, Kahl JS et al. Anthropogenically driven changes in chloride complicate interpretation of base cation trends in lakes recovering from acidic deposition. Environmental Science \& Technology, 2007, 41(22) : 7688-7693.

[11] Luo LC, Qin BQ, Song YZ et al. Seasonal and regional variations in precipitation chemistry in the Lake Taihu Basin, China. Atmospheric Environment, 2007, 41(12): 2674-2679.

[12] Yang F, Yu H, Li L. Effect of wet deposition on water quality and concentration of chlorophyll a in Lake Tai. Hubei Agricultural Sciences, 2014, 53(3) : 28-32. [ 杨凡, 余辉, 李莉. 大气湿沉降对太湖水质及叶绿素 a 的影响. 湖北农业科 学, $2014, \mathbf{5 3}(3): 28-32$.]

[13] Qin BQ, Zhu GW, Gao G et al. A Drinking Water Crisis in Lake Taihu, China: Linkage to climatic variability and lake management. Environmental Management, 2010, 45(1) : 105-112.

[14] Wu YL, Xu H, Yang GJ et al. Progress in nitrogen pollution research in Lake Taihu. J Lake Sci, 2014, 26( 1) : 19-28. DOI: 10.18307/2014.0103. [吴雅丽, 许海, 杨桂军等. 太湖水体氮素污染状况研究进展. 湖泊科学, 2014,26 (1) : 19-28.]

[ 15] Yu T, Zhang Y, Wu FC et al. Six-decade change in water chemistry of large freshwater Lake Taihu, China. Environmental Science \& Technology, 2013, 47(16) : 9093-9101.

[16] Li ZY. Relation between ion concentration and $\mathrm{pH}$ in precipitation in numberof Chinese cities. Acta Scientiae Circumstanti$a e, 1999,19(3)$ : 303-306. [李祚泳. 我国部分城市降水中离子浓度与 pH 值的关系研究. 环境科学学报, 1999, $19(3)$ : 303-306.]

[17] Yu T, Xu QJ, He CD et al. Long-term trends in acid neutralizing capacity under increasing acidic deposition: A special example of eutrophic Taihu Lake, China. Environmental Science \& Technology, 2016, 50(23): 12660-12668.

[18] Qin BQ, Hu CH. Data set of located ecosystem monitoring and study in China ( Taihu Lake Station, Jiangsu Province, 1991-2006) : First edition. Beijing: China Agriculture Press, 2010. [秦伯强, 胡春华. 中国生态系统定位观测与研究 数据集: 湖泊湿地海湾生态系统卷 (江苏太湖站 1991-2006) : 第一版. 北京: 中国农业出版社, 2010.]

[19] Editorial board of " water and wastewater monitoring and analysis method", Ministry of Environmental Protection of People's Republic of China ed. Monitoring and analysis methods of water and wastewater: fourth edition. Beijing: China Environmental Science Press, 2002. [国家环境保护总局《水和废水监测分析方法》编委会. 水和废水监测分析方 法: 第 4 版. 北京: 中国环境科学出版社, 2002.]

[20] Liu JT, Fang SW, Feng Q et al. Analysis of regime shift in Taihu Lake based on Mann-Kendall method. China Environmental Science, 2015, 35(12): 3707-3713. [刘聚涛, 方少文, 冯倩等. 基于 Mann-Kendall 法的湖泊稳态转换突变 分析. 中国环境科学, 2015, 35(12): 3707-3713.]

[21] Gocic M, Trajkovic S. Analysis of changes in meteorological variables using Mann-Kendall and Sen's slope estimator statistical tests in Serbia. Global and Planetary Change, 2013, 100: 172-182.

[22] Tu J, Wang H, Zhang Z et al. Trends in chemical composition of precipitation in Nanjing, China, during 1992-2003. Atmospheric Research, 2005, 73(3) : 283-298.

[23] Sha CY, He WS, Fu CT et al. Analysis on the variation of acidity and chemical compositions of rainwater in Shanghai. Research of Environmental Sciences, 2007, 20(5) : 31-34. [沙晨燕, 何文珊, 童春富等. 上海近期酸雨变化特征及其化 学组分分析. 环境科学研究, 2007, 20(5): 31-34.]

[24] Bernhardt ES. Ecology. Cleaner lakes are dirtier lakes. Science, 2013, 342(6155) : 205-206.

[25] Yu T, Dai D, Lei K et al. $\delta^{15} \mathrm{~N}$ and nutrient stoichiometry of water, aquatic organisms and environmental implications in Taihu lake, China. Environmental Pollution, 2018, 237: 166-173. 
[26] Guo JH, Wang FS, Vogt RD et al. Anthropogenically enhanced chemical weathering and carbon evasion in the Yangtze Basin. Scientific Reports, 2015, 5: 11941-11948.

[27] Dai D, Zhang Y, Han XJ et al. Impact of sewage discharge in Taihu Basin on the water chemistry of Lake Taihu. Acta Scientiae Circumstantiae, 2015, 35(10) : 3121-3130. [代丹, 张远, 韩雪娇等. 太湖流域污水排放对湖水天然水化学的 影响. 环境科学学报, 2015, 35(10): 3121-3130.]

[28] Yu T, Dai D, He C et al. Response of sediment calcium and magnesium species to the regional acid deposition in eutrophic Taihu Lake, China. Environmental Science and Pollution Research, 2016, 23(22) : 22489-22499.

[29] Neary BP, Dillon PJ. Effects of sulphur deposition on lake-water chemistry in Ontario, Canada. Nature, 1988, 333 (6171) : 340-343.

[30] Galloway JN, Norton SA, Church MR. Freshwater acidification from atmospheric deposition of sulfuric acid: A conceptual model. Environmental Science \& Technology, 1983, 17(11) : 541A-545A.

[31] Zhai DX, Yang ZF, Liu QQ et al. Major ion chemistry and influencing factors of rivers in Poyang Lake basin. Earth Science Frontiers, 2012, 19(1): 264-276. [翟大兴, 杨忠芳, 柳青青等. 鄱阳湖流域水化学特征及影响因素分析. 地学前 缘, 2012, 19(1): 264-276].

[32] Hu CH, Zhou WB, Xia SQ. Charcteristics of major ions and the influence factors in Poyang Lake catchment. Environmental Chemistry, 2011, 30(9): 1620-1626. [胡春华, 周文斌, 夏思奇. 鄱阳湖流域水化学主离子特征及其来源分析. 环境化学, 2011, 30(9): 1620-1626.]

[33] Qin BQ, Liu ZW, Havens K. Eutrophication of shallow lakes with special reference to Lake Taihu, China. Springer Science \& Business Media, 2007, 53-61: 135-140.

[34] Wang XJ, Zhang W, Huang YN et al. Modeling and simulation of point-non-point source effluent trading in Taihu Lake area: perspective of non-point sources control in China. Science of the Total Environment, 2004, 325(1) : 39-50.

[35] Cheng ST, Qian CY, Zhang HJ. Estimation and application of macroscopic water environmental capacity of phosphorus and nitrongen for Taihu Lake. Acta Scientiae Circumstantiae, 2013, 33(10): 2848-2855. [程声通, 钱益春, 张红举. 太湖 总磷、总氮宏观水环境容量的估算与应用. 环境科学学报, 2013, 33(10): 2848-2855.]

[36] Yu H, Zhang LL, Yan SW et al. Atmospheric wet deposition characteristics of nitrogen and phosphorus nutrients in Taihu Lake and contributions to the lake. Research of Environmental Sciences, 2011, 24(11): 1210-1219. [余辉, 张璐璐, 燕 姝雯等.太湖氮磷营养盐大气湿沉降特征及人湖贡献率. 环境科学研究, 2011, 24(11): 1210-1219.]

[37] Luo YX. Nitrogen Load of agricultural sources and spatial variations in the Taihu Lake Basin [Dissertation]. Nanjing: Nanjing Agricultural University, 2016: 47. [罗永霞. 太湖流域农业源氮排放及其空间特征 [学位论文]. 南京: 南京 农业大学, 2016: 47.]

[38 ] Amos HM, Jacob DJ, Kocman D et al. Global biogeochemical implications of mercury discharges from rivers and sediment burial. Environmental Science \& Technology, 2014, 48(16) : 9514-9522.

[39] Lu X, Mao Q, Mo J et al. Divergent responses of soil buffering capacity to long-term $\mathrm{n}$ deposition in three typical tropical forests with different land-use history. Environmental Science \& Technology, 2015, 49(7) : 4072-4080.

[40] De Leeuw G, Spokes L, Jickells T et al. Atmospheric nitrogen inputs into the North Sea: effect on productivity. Continental Shelf Research, 2003, 23(17) : 1743-1755.

[41] Song YZ, Qin BQ, Yang LY et al. Primary estimation of atmospheric wet deposition of nitrogen to aquatic ecosystem of Lake Taihu. J Lake Sci , 2005, 17(3) : 226-30. DOI : 10.18307/2005.0306. [宋玉芝, 秦伯强, 杨龙元等. 大气湿沉降 向太湖水生生态系统输送氮的初步估算. 湖泊科学, 2005, 17(3) : 226-30.]

[42] Zhao QH, Sun GD, Wang JJ et al. Coupling effect of water temperature and light energy on the algal growth in Lake Taihu. $J$ Lake Sci, 2018, 30(2) : 385-393. DOI: 10.18307/2018.0210. [ 赵巧华, 孙国栋, 王健健等. 水温、光能对春季太湖 藻类生长的耦合影响. 湖泊科学, $2018,30(2)$ : 385-393.] 